\title{
REMOÇÃO DE RUÍDO EM SISTEMAS DE COMUNICAÇÕES DIGITAIS: UMA NOVA ABORDAGEM
}

\author{
Juraci F. Galdino, Ernesto L. Pinto e Marcelo S. de Alencar
}

\begin{abstract}
Resumo - Uma nova estratégia de pré-processamento foi proposta em [1] para remoção de ruído na entrada de receptores digitais. Esta estratégia se baseia no uso de técnicas de denoising, em contraposição aos procedimentos convencionais, que empregam filtros lineares e invariantes no tempo. O presente artigo contempla a avaliação analítica do desempenho deste tipo de pré-processamento, em canais AWGN, visando o desenvolvimento de ferramentas para futuras investigações da escolha de seus parâmetros. Também são apresentados novos resultados de avaliação de seu desempenho em canais seletivos em freqüência, obtidos via simulação computacional.
\end{abstract}

Palavras-chave: Denoising, remoção de ruído, comunicações digitais, canais seletivos em freqüência.

\begin{abstract}
A novel procedure for noise removal at the receiver front-end was proposed in [1]. This procedure is based on the use of denoising techniques, as opposed to the conventional front-ends which use linear time-invariant filters. An analytical performance evaluation of this procedure in AWGN channels is addressed here. In addition, a new performance comparison with conventional techniques for frequency selective channels is also presented, which is based on computer simulations.
\end{abstract}

Keywords: Denoising, noise removal, frequency selective channels, digital communications.

\section{INTRODUÇÃO}

O efeito do ruído em sistemas de comunicações digitais pode ser combatido com o uso de filtros lineares previamente projetados. Em canais AWGN essa abordagem conduz ao projeto do filtro casado (MF), o qual permite maximizar a relação sinal ruído (RSR) nos instantes de amostragem na taxa de símbolos. Em canais seletivos em freqüência e variantes no tempo muitas das estruturas de processamento de entrada apontam também para o projeto de filtros lineares, no entanto nesse caso filtros previamente projetados não conseguem maximizar a RSR nos instantes de amostragem. Isso poderia ser obtido com o uso de filtros adaptativos, mas essa abordagem pode provocar instabilidades no esquema

Juraci Ferreira Galdino e Ernesto Leite Pinto estão vinculados ao Departamento de Engenharia Elétrica do Instituto Militar de Engenharia, Rio de Janeiro, RJ, Brasil. Marcelo Sampaio de Alencar está vinculado ao Departamento de Engenharia Elétrica da Universidade Federal de Campina Grande, Campina Grande, PB, Brasil. Emails: \{galdino, ernesto\}@ime.eb.br, malencar@dee.ufcg.edu.br. Editor de Área responsável: Abraham Alcaim. Artigo submetido em 13/Jun/2003, revisado em 27/Nov/2003, 17/Mar/2004, aceito em 18/Mai/2004. de recepção devido à necessidade de se utilizar no processamento de entrada símbolos previamente detectados. Uma nova estratégia de combate ao ruído foi proposta em [1], na qual se emprega uma estrutura de processamento de entrada não-linear, implementada no domínio da transformada wavelet. Este tipo de pré-processamento possui diversos componentes e parâmetros que podem ser projetados para minimizar a probabilidade de erro do sistema, de acordo com as características dos sinais transmitidos e do canal.

No presente artigo é desenvolvido um conjunto básico de ferramentas analíticas para futuras investigações da melhoria de desempenho deste tipo de pré-processamento através da escolha criteriosa de seus componentes e parâmetros considerando-se o seu emprego num sistema de comunicação simples, no qual se utiliza modulação BPSK em canal AWGN.

Este artigo ainda inclui novos resultados de avaliação de desempenho obtidos via simulação computacional, em que se considera canais seletivos em freqüência, modulação QPSK e filtros de transmissão e recepção com resposta ao impulso (RI) que se estende além do intervalo de símbolo. Além disso, são empregados equalizadores nos esquemas de recepção. Sob estas condições é feita uma comparação de desempenho entre estratégia de pré-processamento proposta em [1] e outras técnicas usualmente empregadas no mesmo contexto.

$\mathrm{O}$ restante do artigo é dividido em cinco seções. $\mathrm{Na}$ Seção 2 são apresentados os fatores ou aspectos que motivaram o uso de técnicas de denoising no presente contexto. A Seção 3 se destina à discussão de técnicas de denoising que empregam limiar de escopo global. Na Seção 4 obtém-se uma aproximação analítica para a probabilidade de erro de bit considerando canais AWGN e esquemas de modulação BPSK. No final desta seção são apresentados resultados numéricos que ilustram o potencial de utilização das ferramentas analíticas obtidas. Na Seção 5 são apresentados novos resultados de simulação referentes à aplicação do pré-processamento baseado em denoising em canais seletivos em freqüência, avaliando-se o efeito da escolha de alguns de seus parâmetros e fazendo-se também uma comparação de desempenho entre este procedimento e uma estrutura de pré-processamento convencional. Finalmente, na Seção 6 são apresentadas as conclusões do trabalho.

\section{MOTIVAÇÃo PARA O USO DE TÉC- NICAS DE DENOISING EM RECEP- TORES}

Dentre os aspectos que motivaram o uso dessa ferramenta no presente contexto destacam-se: 
- os sinais na saída dos filtros de transmissão são geralmente suaves face à limitação de banda exercida por esses filtros. Essa suavização permite aproximar esses sinais usando poucos coeficientes no domínio da transformada wavelet, contribuindo para o bom desempenho das técnicas de denoising;

- é desnecessário conhecer a resposta ao impulso do canal. Essa talvez seja a característica mais importante do procedimento de denoising, que, em princípio, viabiliza o seu uso em processamentos de entrada para aplicações em receptores cegos e, de maneira geral, em situações nas quais é difícil obter parâmetros relativos à RI do canal;

- os procedimentos de denoising compreendem uma vasta coleção de opções e parâmetros que podem ser projetados para reduzir a probabilidade de erro do sistema de comunicação;

- o procedimento é adequado para processadores digitais, pois funciona basicamente com operações de soma, multiplicação, decimação e expansão.

Em suma, as técnicas de denoising são simples, podem reduzir o nível de ruído sem requerer o conhecimento da RI do canal de comunicação, e incluem, de fato, uma coleção de procedimentos que podem, em princípio, ser projetados para reduzir a probabilidade de erro do sistema.

\section{TÉCNICAS DE DENOISING}

$O$ recente ressurgimento do interesse na estimação nãoparamétrica pode ser atribuído ao aparecimento de funções de bases wavelets e suas propriedades de compactação ou concentração de energia e localização no plano tempofreqüência que motivaram diversas aplicações nas mais variadas áreas do conhecimento humano. De olho nessas propriedades, Donoho e Johnstone em [2] propuseram o uso de funções de base wavelets ortonormais para remover ruído de sinais e a esse procedimento denominaram denoising.

Os procedimentos de denoising atuam diretamente sobre os coeficientes da transformada wavelet da observação ruidosa e se beneficiam da propriedade de concentração da energia dessa transformada que permite representar, com boa fidelidade, as funções do espaço de sinal com uma pequena parcela dos coeficientes da expansão, o que não se verifica para o ruído, principalmente se ele for modelado por um processo com densidade espectral de potência (DEP) plana. Neste caso ele pertence a um espaço funcional de dimensão infinita e, na média, se projeta igualmente em todas as funções de base com coeficientes descorrelacionados. No domínio da transformada os coeficientes são contaminados por ruído com variâncias iguais aquela do ruído presente nas amostras do sinal no domínio do tempo, porém a energia do sinal fica confinada a poucos coeficientes. Em função disso, o nível de ruído pode ser reduzido zerando os coeficientes da expansão que se encontram abaixo de um limiar pré-estabelecido.

$\mathrm{O}$ desempenho do procedimento de denoising depende sensivelmente do limiar de comparação. Segundo Donoho e Johnstone, se este parâmetro for adequadamente escolhido, bons resultados podem ser obtidos para uma vasta gama de sinais [3].

Uma questão basilar referente ao uso da transformada wavelet está relacionada com a escolha da família de funções de base. Nesse tipo de transformada, diversas famílias de funções podem ser usadas para realizar a decomposição, desde que atendam a determinados requisitos.

Para a aplicação de denoising é importante que as referidas funções concentrem a energia do sinal útil em poucos coeficientes da expansão. Quanto maior for essa concentração, mais coeficientes da expansão poderão ser eliminados no processo de síntese sem provocar distorção, promovendo, dessa forma, uma severa redução do nível de ruído. A exploração deste potencial fica no entanto condicionada pela dificuldade de análise matemática da probabilidade de erro de receptores que utilizam este procedimento.

Para canais AWGN e modulação BPSK, foi estabelecido um ponto inicial para uma discussão mais profunda desse tema, obtendo a probabilidade de erro em função do limiar de denoising e da transformada wavelet usada. A partir daí, pode-se tentar a otimização do procedimento no sentido de minimizar a probabilidade de erro do sistema.

\subsection{PRINCíPIOS BÁSICOS}

O problema de interesse consiste em se estimar o sinal $\boldsymbol{x}=\left(x_{1}, \cdots, x_{N_{1}}\right)^{\prime}$ a partir de observaçōes ruidosas $\boldsymbol{y}=$ $\left(y_{1}, \cdots, y_{N_{1}}\right)^{\prime}$ dada por ${ }^{1}$

$$
\boldsymbol{y}=\boldsymbol{x}+\tilde{\boldsymbol{\eta}}
$$

sendo o ruído de observação $\tilde{\eta}=\left(\tilde{\eta}_{1}, \cdots, \tilde{\eta}_{N_{1}}\right)^{\prime}$ modelado por um processo estocástico gaussiano estacionário, com média nula, variância $\sigma^{2}$ e densidade espectral de potência plana.

Os procedimentos de denoising tomam a transformada wavelet discreta (DWT, da expressão em inglês Discrete Wavelet Transform) de $\boldsymbol{y}$ e passam os coeficientes da transformada por um processador não-linear, no qual as amplitudes desses coeficientes são comparadas com um limiar $\lambda$. Os coeficientes cujas amplitudes estiverem abaixo do limiar de comparação são igualados a zero e os que estiverem acima podem ser mantidos inalterados ou terem suas amplitudes reduzidas, de acordo com o esquema de denoising adotado. A estimativa de $\boldsymbol{x}$, que será denotada por $\hat{\boldsymbol{x}}$, é obtida realizando a transformada wavelet inversa (IDWT, da expressão em inglês Inverse Discrete Wavelet Transform) dos coeficientes resultantes (Figura 1).

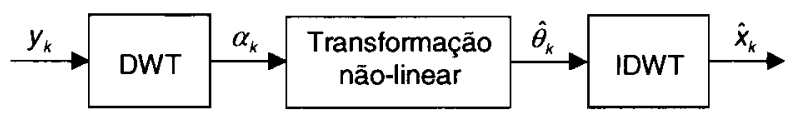

Figura 1. Diagrama de bloco do procedimento de denoising.

As técnicas de denoising consideradas nesta seção são denominadas de técnicas de escopo global e se caracterizam por empregarem apenas um limiar, em contraposição aos

${ }^{1}(\cdot)^{\prime}$ denota a matriz ou o vetor transposto de $(\cdot)$. 


\section{Juraci F. Galdino, Ernesto L. Pinto e Marcelo S. Alencar \\ Remoção de Ruído em Sistemas de Comunicações Digitais: Uma Nova Abordagem.}

procedimento de escopo local, que adotam diversos limiares de comparação. Esta segunda abordagem é empregada na próxima seção e apresenta algumas vantagens para os casos que envolvem ruído colorido.

O procedimento descrito anteriormente será agora detalhado. Denotando por $\boldsymbol{\alpha}=\left(\alpha_{1}, \cdots, \alpha_{N_{2}}\right)^{\prime}$ o vetor cujas componentes representam os coeficientes da transformada wavelet discreta de $\boldsymbol{y}$, tem-se

$$
\alpha=W y,
$$

na qual $\boldsymbol{W}$ é uma matriz de dimensão $N_{2} \times N_{1}$ que representa o operador linear responsável pela realização da transformada wavelet.

De forma similar, denotando por $\boldsymbol{\theta}=\left(\theta_{1}, \cdots, \theta_{N_{2}}\right)^{\prime}$ e $\boldsymbol{\eta}=\left(\eta_{1}, \cdots, \eta_{N_{2}}\right)^{\prime}$ os coeficientes das transformadas wavelet discretas de $\boldsymbol{x}$ e $\tilde{\boldsymbol{\eta}}$, respectivamente, a Equação 1 pode ser reescrita no domínio da transformada wavelet da seguinte maneira

$$
\alpha=\boldsymbol{\theta}+\boldsymbol{\eta} .
$$

Os procedimentos de denoising utilizam funções de base wavelets ortonormais. Assim sendo,

$$
\boldsymbol{W}^{\prime} \boldsymbol{W}=\boldsymbol{I}
$$

em que $I$ é a matriz identidade de dimensão $N_{1} \times N_{1}{ }^{2}$.

Inicialmente foram propostos dois procedimentos para obter os coeficientes modificados a partir da comparação com o limiar $\lambda$, denotados por $\hat{\boldsymbol{\theta}}=\left(\hat{\theta}_{1}, \hat{\theta}_{2}, \cdots, \hat{\theta}_{N_{2}}\right)^{\prime}$. Um deles adota um limiar abrupto e o outro um limiar suave. Posteriormente, outros mecanismos foram propostos e uma discussão sobre eles pode ser encontrada em [4].

O sinal estimado na saída do procedimento de denoising, $\hat{\boldsymbol{x}}$, é dado por

$$
\hat{\boldsymbol{x}}=\boldsymbol{W}^{\prime} \hat{\boldsymbol{\theta}} .
$$

No procedimento com limiar suave se um coeficiente possui amplitude menor do que o limiar, ele é igualado a zero. Do contrário, sua amplitude é reduzida por uma quantidade igual ao limiar. Nesse caso, $\hat{\theta}_{i}$ para todo $i \in\left[1, \cdots, N_{2}\right]$ fica dado por

$$
\hat{\theta}_{i}=\left\{\begin{array}{ll}
\operatorname{sgn}\left(\alpha_{i}\right)\left(\left|\alpha_{i}\right|-\lambda\right), & \left|\alpha_{i}\right|>\lambda \\
0, & \left|\alpha_{i}\right| \leq \lambda
\end{array},\right.
$$

em que sgn $(\cdot)$ denota a função sinal.

Para uma mesma família de funções de base wavelets, o desempenho das técnicas de denoising depende basicamente do limiar $\lambda$ e da estratégia de mapeamento. Em [3] e [2] foi proposto o limiar

$$
\lambda_{u}=\sigma \sqrt{2 \log N_{1}},
$$

denominado limiar universal, que segundo os autores produz bons padrões de desempenho.

A partir do trabalho seminal de Donoho muitos esquemas de denoising foram e continuam sendo propostos. Técnicas

\footnotetext{
${ }^{2}$ Devido às sucessivas operaçōes de convolução realizadas para obter a transformada wavelet discreta, em geral $N_{2} \geq N_{1}$ e $\boldsymbol{W}^{\prime}$ representa, na realidade, a inversa à esquerda de $\boldsymbol{W}$.
}

desenvolvidas para ruído colorido, com base na teoria de teste de hipóteses e na estimação bayesiana são alguns dos esquemas que vêm sendo apresentados recentemente em congressos e em revistas especializadas. Trabalhos interessantes que discutem essas e outras alternativas são comentados em [4].

\section{ANÁLISE DE DESEMPENHO EM CANAIS AWGN}

O diagrama de blocos simplificado de um sistema de comunicações que emprega denoising no processamento de entrada do receptor é mostrado na Figura 2. Neste caso, a estrutura de pré-processamento consiste basicamente de um filtro limitador de faixa, um amostrador na taxa $P / T$, sendo $P$ o fator de superamostragem, células de memória (buffer), processador de denoising e decimador.

Na discussão que se segue é admitido que o filtro elimina o ruído faixa larga mas mantém sua DEP plana dentro da banda passante do sinal de interesse, que a taxa de amostragem é superior à taxa de símbolos e que o buffer acumula as amostras necessárias para viabilizar o procedimento de denoising, o qual é realizado em lotes. Além disso, a discussão considera o esquema de modulação BPSK, canais caracterizados pelo modelo AWGN e procedimentos de denoising que empregam mapeamento suave com limiar de escopo global. $O$ algoritmo de recepção opera na taxa de símbolos, por esse motivo foi incluído um decimador na saída do processamento de entrada.

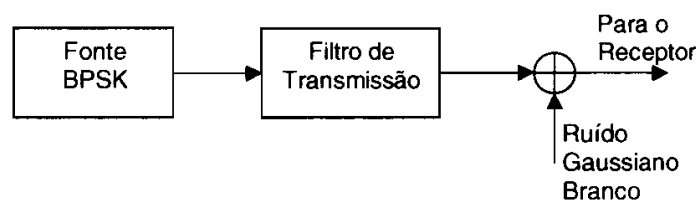

(a) Transmissor e Canal

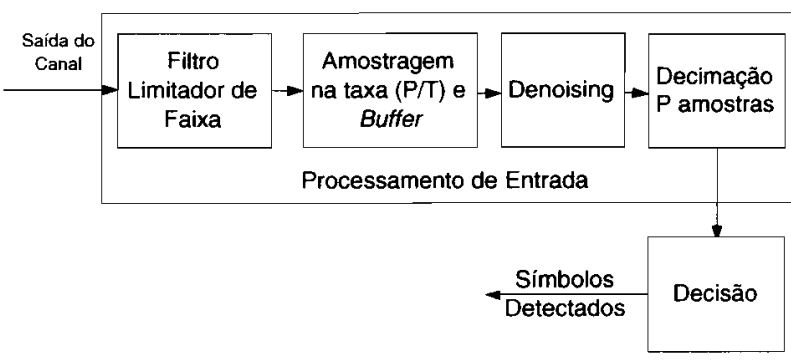

(b) Receptor

Figura 2. Diagrama de blocos de um sistema de comunicação que emprega o processamento de entrada baseado em denoising.

O sinal armazenado no buffer no $n$-ésimo intervalo de símbolo é dado pela Equação $1 \mathrm{com} N_{1}=P$. Neste caso, o ruído de observação é modelado por um processo gaussiano branco com média nula e variância $\sigma^{2}$ e $\boldsymbol{x}=s_{n} \boldsymbol{h}_{T}$, sendo $s_{n}$ o $n$-ésimo símbolo transmitido e $\boldsymbol{h}_{T}$ o pulso básico de transmissão, que se admite possuir duração igual ou inferior 
ao intervalo de símbolo. Assume-se também que os símbolos transmitidos são IID e extraídos do conjunto $\{-1,1\}$.

De acordo com o resultados analíticos apresentados em [5], para um dado $s_{n}$, tem-se que

$$
\hat{\boldsymbol{\theta}}=\boldsymbol{\theta} \odot \boldsymbol{U}+\boldsymbol{\eta} \odot \boldsymbol{U}-\lambda \boldsymbol{V}
$$

em que $\odot$ denota o produto de Hadamard [6], $\boldsymbol{\eta}$ é um vetor aleatório gaussiano, $\boldsymbol{U}=\left(U_{1}, \cdots, U_{N_{2}}\right)^{\prime}$ e $\boldsymbol{V}=$ $\left(V_{1}, \cdots, V_{N_{2}}\right)^{\prime}$ por sua vez são vetores aleatórios cujas componentes são dadas por:

$$
U_{i}=\left\{\begin{array}{ll}
0, & \text { se }\left|\theta_{i}+\eta_{i}\right| \leq \lambda \\
1, & \text { se }\left|\theta_{i}+\eta_{i}\right|>\lambda
\end{array},\right.
$$

$\mathrm{e}$

$$
V_{i}= \begin{cases}-1, & \theta_{i}+\eta_{i}<-\lambda \\ 0, & \left|\theta_{i}+\eta_{i}\right| \leq \lambda \\ 1, & \theta_{i}+\eta_{i}>\lambda\end{cases}
$$

tendo fdps dadas por

$$
f_{U}(U)=\left(1-p_{i}\right) \delta(U)+p_{i} \delta(U-1)
$$

e

$$
f_{V,}(V)=\tilde{q}_{i} \delta(V+1)+\left(1-p_{i}\right) \delta(V)+q_{i} \delta(V-1) .
$$

Nessas equações $\delta(\cdot)$ representa a função impulso unitário e

$$
\begin{gathered}
p_{i}=\operatorname{Pr}\left(\left|\xi_{i}\right|>\lambda\right), \\
q_{i}=\operatorname{Pr}\left(\xi_{i}>\lambda\right), \\
\tilde{q}_{i}=\operatorname{Pr}\left(\xi_{i}<-\lambda\right)=p_{i}-q_{i}
\end{gathered}
$$

$\operatorname{com} \xi_{i}$ sendo uma VA gaussiana de média $\theta_{i}$ e variância $\sigma^{2}$.

Alguns pontos importantes relacionados com o funcionamento do processamento de entrada baseado em denoising podem ser discutidos com base nas Equações 5, 8, 10, $11 \mathrm{e}$ 12. Vê-se claramente que o sinal $x$ depende da informação transmitida (embutida em $\boldsymbol{\theta}$ ), do limiar de comparação e da transformada wavelet, dependências essas evidentes de antemão, mas que agora foram explicitadas matematicamente.

A segunda parcela do lado direito da Equação 8 decorre do ruído que não é eliminado pelo processo de denoising. Esta parcela é responsável pela variância do estimador. Por outro lado, os termos do primeiro somatório para os quais $U_{i}=0$, juntamente com a terceira parcela do lado direito desta equação, contribuem para a polarização do estimador.

Conforme pode ser verificado nas Equações 11 e 12, para um dado conjunto de funções de base wavelets, à medida que $\lambda$ aumenta, a probabilidade de que $U_{i}=0$ também aumenta, causando o aumento da polarização e a redução da variância do estimador. No tocante à terceira parcela, o comportamento com $\lambda$ é mais complexo, pois a probabilidade de que $V_{i} \neq 0$ se reduz com o aumento de $\lambda$. Para este termo, o aumento de $\lambda$ causa um aumento das parcelas que compõem o somatório, mas também uma redução na quantidade de parcelas não-nulas.

Denotando por $i_{s}$ o índice do instante de amostragem dentro do intervalo de símbolo, a entrada do decisor referente ao $n$-ésimo intervalo de símbolo é expressa por

$$
\hat{x}_{i_{*}}=\boldsymbol{W}\left(i_{s},:\right)^{\prime} \hat{\boldsymbol{\theta}}
$$

sendo $\boldsymbol{W}\left(i_{s},:\right)^{\prime}$ a $i_{s}$-ésima coluna de $\boldsymbol{W}$.

A fim de analisar o desempenho do sistema, é importante inicialmente encontrar a fdp de $\hat{\theta}_{i}$. No desenvolvimento que conduziu à determinação dessa fdp, as seguintes propriedades estatísticas foram utilizadas:

- as VAs $\left\{\eta_{i}\right\}$ são estatísticamente independentes. Este fato decorre do uso de funções de base ortonormais e do modelo de ruído adotado;

- a independência estatística das VAs $\left\{\eta_{i}\right\}$ faz com que as variáveis aleatórias $\left\{U_{i}\right\}$ e $\left\{V_{i}\right\}$ sejam independentes entre si.

Considerando essas propriedades, foi mostrado em [5] que a fdp de $\hat{\theta}_{i}$ condicionada a transmissão do símbolo $s_{n}$ é dada por

$$
\begin{aligned}
& f_{\hat{\theta}}(\zeta)=\left(1-p_{i}\right) \delta(\zeta)+ \\
& \frac{1}{\sqrt{2 \pi} \sigma} \exp \left[-\frac{\left(\zeta-\theta_{i}+\lambda\right)^{2}}{2 \sigma^{2}}\right] \mathrm{u}(\zeta)+ \\
& \frac{1}{\sqrt{2 \pi} \sigma} \exp \left[-\frac{\left(\zeta-\theta_{i}-\lambda\right)^{2}}{2 \sigma^{2}}\right] \mathrm{u}(-\zeta)
\end{aligned}
$$

na qual u(·) é a função degrau unitário.

$\hat{E}$ importante verificar que para $\lambda=0$ (processamento de entrada sem denoising), tem-se $p_{i}=1$ e $f_{\hat{\theta}_{i}}(\cdot)$ fica dada por uma fdp gaussiana com média $\theta_{i}$ e variância $\sigma^{2}$, para todo $i$, como esperado. Por outro lado, quando $\lambda \rightarrow \infty$, tem-se $p_{i} \rightarrow 0$ e $f_{\hat{\theta}_{i}}(\cdot) \rightarrow \delta(\cdot)$, o que também é esperado pois, para sinais de energia, que são os de interesse neste trabalho, é impossível que algum coeficiente supere o limiar neste caso.

De acordo com a Equação $13, \hat{x}_{i_{*}}$ é dada pela combinação linear das variáveis aleatórias $\hat{\theta}_{i}$ com pesos dados pelas entradas da $i_{s}$-ésima coluna da matriz wavelet. Como mostrado em [5], as variáveis aleatórias $\hat{\theta}_{i}$ são estatisticamente independentes. Portanto, a fdp de $\hat{x}_{i,}$ é obtida pela convolução das fdps das variáveis aleatórias $\kappa_{i} \triangleq \boldsymbol{W}\left(i, i_{s}\right) \hat{\theta}_{i}$, cuja aproximação analítica é considerada a seguir.

Define-se $Z_{k}$ como a soma parcial das variáveis aleatórias $\kappa_{i}$,

$$
Z_{k} \triangleq \sum_{i=1}^{k} \kappa_{i}, \quad 1 \leq k \leq N
$$

e se denota os momentos de ordem $m$ de $Z_{k}, \kappa_{i}, \hat{x}_{i,}$ e $\hat{\theta}_{i}$, respectivamente, por:

$$
\begin{aligned}
\mu_{Z}^{m}(k) & =\mathrm{E}\left(Z_{k}^{m}\right), \\
\mu_{\kappa,}(m) & =\mathrm{E}\left(\kappa_{i}^{m}\right), \\
\mu_{\hat{x}}(m) & =\mathrm{E}\left(\hat{x}_{i_{*}}^{m}\right)
\end{aligned}
$$

e

$$
\mu_{\hat{\theta}_{i}}(m)=\mathrm{E}\left(\dot{\theta}_{i}^{m}\right) .
$$

Os momentos de $Z_{k}$ podem ser expressos pela seguinte forma recursiva [7, Pág. 109]

$$
\mu_{Z}^{m}(k)=\sum_{p=0}^{m}\left(\begin{array}{l}
m \\
p
\end{array}\right) \mu_{Z}^{p}(k-1) \mu_{\kappa_{k}}(m-p) k>1 .
$$


Lembrando que

$$
\mu_{\hat{x}}(m)=\mu_{Z}^{m}(N),
$$

e combinando as Equações 17 e 18, verifica-se que para determinar os momentos de $\hat{x}_{i}$. é preciso apenas obter os momentos das VAs $\left\{\theta_{i}\right\}$, visto que a relação entre estes momentos e os momentos de $\kappa_{i}$ é

$$
\mu_{\kappa_{i}}(m)=W\left(i, i_{s}\right)^{m} \mu_{\theta_{i}}(m) .
$$

Conforme mostrado em [5] os momentos de $\hat{\theta}_{i}$ são dados por:

$$
\mu_{\hat{\theta}}(0)=1
$$

$\mathrm{e}$

$$
\mu_{\hat{\theta}_{i}}(m)=\mu_{m}^{1}+\mu_{m}^{2}, \text { para } m \geq 1
$$

com

$$
\begin{aligned}
& \mu_{m}^{1}=(m-1) \sigma^{2} \mu_{m-2}^{1}+\left(\theta_{i}-\lambda\right) \mu_{m-1}^{1}, \\
& \mu_{m}^{2}=(m-1) \sigma^{2} \mu_{m-2}^{2}+\left(\theta_{i}+\lambda\right) \mu_{m-1}^{2} .
\end{aligned}
$$

As equações recorrentes apresentadas acima são válidas para $m \geq 2$, com as seguintes condições iniciais:

$$
\begin{aligned}
& \mu_{0}^{1}=\theta_{i}, \\
& \mu_{1}^{1}=\left(\theta_{i}-\lambda\right)+\frac{\sigma}{\sqrt{2 \pi}} \exp \left[-\frac{\left(\theta_{i}-\lambda\right)^{2}}{2 \sigma^{2}}\right], \\
& \mu_{0}^{2}=p_{i}-q_{i}
\end{aligned}
$$

$$
\mu_{1}^{2}=\left(\theta_{i}+\lambda\right)-\frac{\sigma}{\sqrt{2 \pi}} \exp \left[-\frac{\left(\theta_{i}+\lambda\right)^{2}}{2 \sigma^{2}}\right]
$$

Tendo sido determinados os momentos de $\hat{x}_{i_{\text {, }}}$, pode-se empregar uma técnica baseada em momentos para aproximar analiticamente a fdp do sinal na entrada do decisor.

\subsection{APROXIMAÇÃO ANALÍTICA DE FDP USANDO TÉCNICAS DOS MOMENTOS}

A aproximação de fdp usando momentos estatísticos é um campo vasto de investigação, para o qual há vários procedimentos propostos, dentre os quais destacam-se: a regra da quadratura de Gauss (RQG), a série de Edgeworth (SE), a série de Gram-Charlier (SGC) e a maximização da entropia $(\mathrm{ME})^{3}$.

Inicialmente, as quatro técnicas supracitadas foram empregadas no sentido de obter a aproximação da fdp de $\hat{x}_{i_{*}}$ usando os momentos deduzidos na seção anterior. No entanto, os desempenhos obtidos não foram satisfatórios. Algumas das técnicas, como a SGC, a SE e a ME, geraram aproximações com valores negativos nas caudas e nas proximidades da descontinuidade (mostra-se adiante que há uma

\footnotetext{
${ }^{3} \mathrm{Em}$ [5] essas técnicas são discutidas e são apresentadas várias referências nesse assunto.
}

descontinuidade nesta fdp). Para a RQG as funções geradas não apresentaram valores negativos, o que é garantido por construção, mas as curvas de desempenho obtidas usando as fdps aproximadas divergiram grosseiramente daquelas obtidas por simulação computacional.

Màlgrado não existir uma prova cabal, provavelmente esses resultados se explicam pela presença conjunta de impulso e descontinuidade na fdp de $\hat{\theta}_{i}$, o que, apesar das sucessivas operações de convolução para gerar $\hat{x}_{i_{*}}$, faz com que a fdp desta VA, denotada por $f_{\hat{x}}$, possua também um impulso e descontinuidade. Investigou-se então uma forma alternativa de emprego dos métodos acima citados na aproximação desejada.

O impulso em $\hat{x}_{i_{i}}$ não representa um sério problema pois sua localização e peso podem ser determinados analiticamente sendo, portanto, possível excluí-lo do processo de aproximação da fdp alvo. No entanto, a descontinuidade não pode ser tratada da mesma forma, pois ela afeta todos os momentos de forma desconhecida.

Diante do exposto, as operações de convolução foram expandidas e os termos relacionados com o impulso e com a descontinuidade foram identificados. O procedimento adotado será discutido a seguir.

A fdp de $\kappa_{i}$ pode ser expressa da seguinte maneira

$$
f_{\kappa_{i}}(\zeta)=P_{i} \delta(\zeta)+f_{i}(\zeta)
$$

com

$$
\begin{gathered}
f_{i}(\zeta) \triangleq \frac{1}{\sqrt{2 \pi w_{i}^{2}} \sigma}\left\{\exp \left[-\frac{\left(\zeta-\left(\theta_{i}-\lambda\right) w_{i}\right)^{2}}{2 \sigma^{2} w_{i}^{2}}\right] \mathrm{u}(\zeta)\right. \\
\left.+\exp \left[-\frac{\left(\zeta-\left(\theta_{i}+\lambda\right) w_{i}\right)^{2}}{2 \sigma^{2} w_{i}^{2}}\right] \mathrm{u}(-\zeta)\right\} .
\end{gathered}
$$

e $P_{i} \triangleq 1-p_{i}$, sendo $\left\{w_{i}\right\}$ extraídos dentre os elementos não nulos da $i_{s}$-coluna da matriz wavelet.

Considerando essas definições, a fdp de $\hat{x}_{i,}$ pode ser escrita por

$$
\begin{aligned}
f_{\hat{x}}(\zeta)= & \left(P_{0} \delta(\zeta)+f_{0}(\zeta)\right) \otimes \cdots \\
& \otimes\left(P_{K-1} \delta(\zeta)+f_{K-1}(\zeta)\right) \\
= & \left.\bigotimes_{i=0}^{K-1} P_{i} \delta(\zeta)+f_{i}(\zeta)\right),
\end{aligned}
$$

na qual $K$ representa a quantidade de valores não nulos de $W\left(:, i_{s}\right)$, portanto, $K \leq N$, e $\otimes$ denota a operação de convolução.

Utilizando as propriedades de distributividade e linearidade do operador convolução, a Equação 25 pode ser rees- 
crita da seguinte maneira

$$
\begin{aligned}
& f_{\hat{x}}(\zeta)=\delta(\zeta) \prod_{i=0}^{K-1} P_{i}+\sum_{i=0}^{K-1}\left(f_{i}(\zeta) \prod_{j=0, j \neq i}^{K-1} P_{j}\right) \\
& +\sum_{i=1}^{l_{2}(K)}\left[\left(\prod_{j \neq V_{2}(i)} P_{j}\right)\left(\underset{\substack{V_{2}(i .2) \\
i=V_{2}(i .1)}}{\otimes} f_{i}(\zeta)\right)\right]+\cdots \\
& +\sum_{i=1}^{l_{K-1}(k)}\left[\left(\prod_{j \neq V_{K-1}(i)} P_{j}\right)(\underbrace{V_{K-1}(i . K-1)}_{i=V_{K-1}(i .1)} f_{i}(\zeta))\right] \\
& +\bigotimes_{i=0}^{k-1} f_{i}(\zeta),
\end{aligned}
$$

em que $l_{j}(m)$ é um inteiro que denota a quantidade de termos formados convoluindo $j$ funçôes, considerando que existem $m$ entradas não nulas em $W\left(:, i_{s}\right)$. É possível obter a seguinte relação de recorrência

$$
l_{j}(k)=l_{j-1}(k-1)+l_{j}(k-1),
$$

cujas condições de contorno são:

$$
\begin{aligned}
& l_{k}(k)=1, \text { para } \forall k, k \leq K \\
& l_{1}(k)=1, \text { para } \forall k, k \leq K \mathrm{e} \\
& l_{j}(k)=0, \text { para } \forall k, j \operatorname{com} k>j \text { e } k \leq K .
\end{aligned}
$$

Ainda com relação à Equação $26, V_{j}$ é uma matriz de índices de dimensão $l_{j}(k) \times j$. Cada linha dessa matriz contém os índices das funções que compõem a convolução. Por exemplo, considerando $k=4$, com índices $0,1,2$ e 3, e $j=2$, então $l_{2}(4)=6 \mathrm{e}$

$$
V_{2}=\left(\begin{array}{ll}
0 & 1 \\
0 & 2 \\
0 & 3 \\
1 & 2 \\
1 & 3 \\
3 & 2
\end{array}\right)
$$

Definindo os parâmetros $A_{i}$ e $A$ como

$$
A_{i}=\prod_{j=0 . j \neq i}^{K-1} P_{j}, \quad A=\prod_{i=0}^{K-1} P_{i}
$$

tem-se

$$
\begin{aligned}
& f_{\hat{x}}(\zeta)=A \hat{\delta}(\zeta)+\sum_{i=0}^{K-1} f_{i}(\zeta) A_{i} \\
& +\sum_{i=1}^{l_{2}(K)}\left(A_{V_{2}(i)} \underset{i=V_{2}(i, 1)}{V_{2}(i, 2)} f_{i}(\zeta)\right)+\cdots \\
& +\sum_{i=1}^{l_{K-1}(k)}\left(A_{V_{K-1}(i)}{\stackrel{V_{K-1}(i, K-1)}{\otimes}}_{i=V_{K-1}(i, 1)} f_{i}(\zeta)\right) \\
& +\bigotimes_{i=0}^{K-1} f_{i}(\zeta) \text {. }
\end{aligned}
$$

O primeiro termo do lado direito da Equação 31 representa um impulso em zero com amplitude conhecida. Já o segundo termo é uma soma ponderada das funções $\left\{f_{i}(\cdot)\right\}$, na qual tanto essas funções quanto os termos de ponderação são conhecidos, sendo este termo responsável pela presença do impulso e da descontinuidade na fdp $f_{\hat{x}}$.

A Equação 31 contém um total de

$$
\sum_{m=1}^{K} l_{m}(K)=2^{K}
$$

parcelas, das quais $K+1$ são conhecidas (o impulso e o segundo somatório do lado direito da referida equação). Obtém-se a seguir uma forma alternativa para a parcela desconhecida $f_{\hat{x}}$, por meio da análise da contribuição desta parcela para a função característica da VA $\hat{x}$.

Considerando a Equação (31), a função característica da VA $\hat{x}_{i_{*}}$, representada por $C_{\hat{x}}$, pode ser expressa por

$$
\begin{aligned}
C_{\hat{x}}(w)= & A+\sum_{i=0}^{K-1} C_{i}(w) A_{i} \\
& +\sum_{i=1}^{l_{2}(K)}\left(A_{V_{2}(i)} \prod_{i=V_{2}(i, 1)}^{V_{2}(i, 2)} C_{i}(w)\right)+\cdots \\
& +\sum_{i=1}^{l_{K-1}(k)}\left(A_{V_{K-1}(i)} \prod_{i=V_{K-1}(i, 1)}^{V_{K-1}(i, K-1)} C_{i}(w)\right) \\
& +\prod_{i=0}^{K-1} C_{i}(w) .
\end{aligned}
$$

A expressão acima pode ser reescrita como

$$
C_{\hat{x}}(w)=S(w)+R(w),
$$

sendo,

$$
S(w)=A+\sum_{i=0}^{K-1} A_{i} C_{i}(w)
$$

com

$$
C_{i}(w)=\int_{-\infty}^{\infty} f_{i}(x) e^{j w x} d x
$$

$\mathrm{e}$

$$
\begin{aligned}
R(w)= & \sum_{i=1}^{l_{2}(K)}\left(A_{V_{2}(i)} \prod_{i=V_{2}(i, 1)}^{V_{2}(i .2)} C_{i}(w)\right)+\cdots \\
& +\sum_{i=1}^{l_{K-1}(k)}\left(A_{V_{K-1}(i)} \prod_{i=V_{K-1}(i, 1)}^{V_{K-1}(i, K-1)} C_{i}(w)\right) \\
& +\prod_{i=0}^{K-1} C_{i}(w) .
\end{aligned}
$$

Note-se que $R(w)$ corresponde à parte desconhecida de $f_{\hat{x}}$. Admitindo duas expansões convenientes em sinais de potência, para $C_{i}(w)$ e $C_{\hat{x}}(w)$, propõe-se a seguir o emprego de métodos baseados em momentos para se obter uma aproximação desta parcela desconhecida de $f_{\hat{x}}$. 
Supondo que $C_{i}(w)$ pode ser representado por

$$
C_{i}(w)=\sum_{l=0}^{\infty} \frac{(j w)^{l} \mu_{i}(l)}{l !}
$$

com

$$
\mu_{i}(m)= \begin{cases}\mu_{\kappa_{i}}(m) & \text { se } m \geq 1 \\ 1-P_{i} & \text { se } m=0\end{cases}
$$

pode-se expressar $S(w)$ como

$$
S(w)=\sum_{l=0}^{\infty} \frac{(j w)^{l} \mu_{s}(l)}{l !}
$$

com

$$
\mu_{s}(l)= \begin{cases}\sum_{i=0}^{K-1} A_{i} \mu_{i}(l) & \text { se } l \geq 1 \\ A+\sum_{i=0}^{K-1} A_{i} \mu_{i}(0) & \text { se } l=0\end{cases}
$$

Supondo também uma expansão para $C_{\hat{x}}(w)$ do tipo

$$
C_{\hat{x}}(w)=\sum_{k=0}^{\infty} \frac{(j w)^{k} \mu_{\hat{x}}(k)}{k !}
$$

$R(\cdot)$ pode ser expressa da seguinte maneira

$$
R(w)=\sum_{l=0}^{\infty} \frac{(j w)^{l} \mu_{r}(l)}{l !},
$$

com

$$
\mu_{r}(l)=\mu_{g}(l)-\mu_{s}(l)
$$

A partir das equações dadas acima $R(\cdot)$ e $S(\cdot)$ podem ser vistas como funções caracteristicas das "variáveis aleatórias" $r$ e $s$, a menos de uma constante de normalização. Tomando a transformada de Fourier inversa obtém-se

$$
f_{\hat{x}}(\zeta)=A \delta(\zeta)+\sum_{i=0}^{K-1} f_{i}(\zeta) A_{i}+f_{r}(\zeta)
$$

na qual $A,\left\{A_{i}\right\}$ e as funções $\left\{f_{i}(\cdot)\right\}$ são conhecidas.

Portanto, a fdp de $\hat{x}_{i s}$ pode ser determinada a partir de $f_{r}(\cdot)$. Vale lembrar que os momentos de $r$ são conhecidos e que $f_{r}(\cdot)$ é continua. Assim sendo, é provável que se possa obter uma boa aproximação analítica para $f_{r}(\cdot)$ usando uma das técnicas dos momentos.

Admitindo que tal aproximação de $f_{r}(\cdot)$, denotada por $\hat{f}_{r}(\cdot)$, tenha sido obtida, a aproximação analítica da fdp de $\hat{x}_{i,}$ pode ser representada por

$$
\hat{f}_{\hat{x}}(\zeta)=A \delta(\zeta)+\sum_{i=0}^{K-1} A_{i} f_{i}(\zeta)+\hat{f}_{r}(\zeta)
$$

\subsection{CÁLCULO DA PROBABILIDADE DE ERRO}

A partir da aproximação analítica da função densidade de probabilidade condicionada apresentada na Equação 46, mostrou-se em [5] que o limiar de decisão ótimo, no sentido de reduzir a probabilidade de erro do sistema de comunicação é zero. Este resultado é importante, pois como o procedimento de denoising é não-linear e polarizado, não havia confirmação prévia acerca desse fato. Assim sendo. a probabilidade de erro do sistema fica dada por

$$
P_{e}=\operatorname{Pr}\left(\hat{x}_{i}>0 \mid s_{n}=-1\right) .
$$

Considerando a Equação 47, a aproximação analítica da probabilidade de erro, que é denotada por $\hat{P}_{e}$, fica dada por

$\hat{P}_{e}=\frac{A}{2}+\frac{1}{2} \sum_{i=0}^{K-1} A_{i} \tilde{\Phi}_{G}\left(\frac{-\hbar_{i}+\lambda}{\sqrt{2} \sigma}\right)+\int_{0}^{\infty} \hat{f}_{r}(\tau) d \tau$,

sendo $\tilde{\Phi}_{G}(\cdot)$ definida por,

$$
\tilde{\Phi}_{G}\left(x_{0}\right) \triangleq \frac{2}{\sqrt{\pi}} \int_{x_{11}}^{\infty} \exp \left(-\tau^{2}\right) d \tau
$$

e $\hbar=\left(\hbar_{1}, \hbar_{2}, \cdots, \hbar_{N_{2}}\right)^{\prime}$ a DWT da RI do pulso de transmissão.

É importante ressaltar que, dependendo da técnica dos momentos empregada, a integral presente na Equação 48 tem uma forma fechada.

De acordo com a Equação 48 , a probabilidade de erro do sistema fica explicitamente determinada em função do limiar de denoising e implicitamente pelas funções de base da transformada wavelet, cuja dependência se reflete nos valores assumidos por $\hbar, A$ e $\left\{A_{i}\right\}$.

\subsection{RESULTADOS NUMÉRICOS}

Esta seção apresenta alguns resultados de simulação computacional de um sistema de comunicação cujo canal é caracterizado pelo modelo AWGN, e que emprega modulação BPSK e o processamento de entrada baseado em denoising. O objetivo principal é comparar os resultados de avaliação de desempenho obtidos via simulação com os gerados a partir da análise apresentada na seção anterior .

O diagrama de blocos do sistema utilizado para esta avaliação de desempenho foi portanto o apresentado na Figura 2, no qual, o filtro limitador de faixa não distorce a forma do pulso básico. A RI do filtro de transmissão é dada pelo pulso de Hanning. ${ }^{4}$

Nas figuras que se seguem são mostradas curvas de desempenho que foram obtidas analiticamente e via simulação computacional. Os resultados analíticos foram obtidos aproximando a Equação 48 pela série de Gram-Charlier com seis momentos.

Considerou-se wavelets dadas pelas funções de base de Haar e de Daubechies. Nesse último caso, foram empregadas as famílias conhecidas como Daubechies-2 e Daubechies-3, aqui denotados por $\mathrm{Db} 2$ e $\mathrm{Db} 3$, respectivamente [8].

$\mathrm{Na}$ Figura 3 são mostradas curvas de taxa de erro de bit em função do limiar de denoising, considerando uma RSR de $4 \mathrm{~dB}$ e $P=32$. A RSR é expressa em termos da razão

${ }^{4}$ Como pode ser verificado na Equação 48 , o formato do pulso de transmissão influencia o desempenho do sistema proposto. No entanto, devido à grande quantidade de parâmetros que afetam o desempenho deste sistema. optou-se por fixar esse formato de pulso. 
entre a potência do sinal transmitido e a do ruído na saída do filtro de recepção que foi considerado ideal com largura de faixa igual a $P / T$. Com essas especificações o ruído que contamina as amostras do sinal na entrada do procedimento de denoising possui DEP plana. Além disso, a DWT é obtida considerando três níveis de resolução $(J=3)$ e as funções de base wavelets Db1 e Db2.

Na Figura 4 são apresentadas curvas de taxa de erro de bit (BER) em função do limiar de denoising, considerando $P=16$, funções de base wavelet $\mathrm{Db} 1, J=2$, e três valores de RSR. Por fim, na Figura 5 são apresentadas curvas de desempenho em função do limiar de denoising considerando $P=32$, funções de base wavelet $\mathrm{Db} 1, \mathrm{RSR}=4 \mathrm{~dB}$, e $J=2$, 3 e 5 .

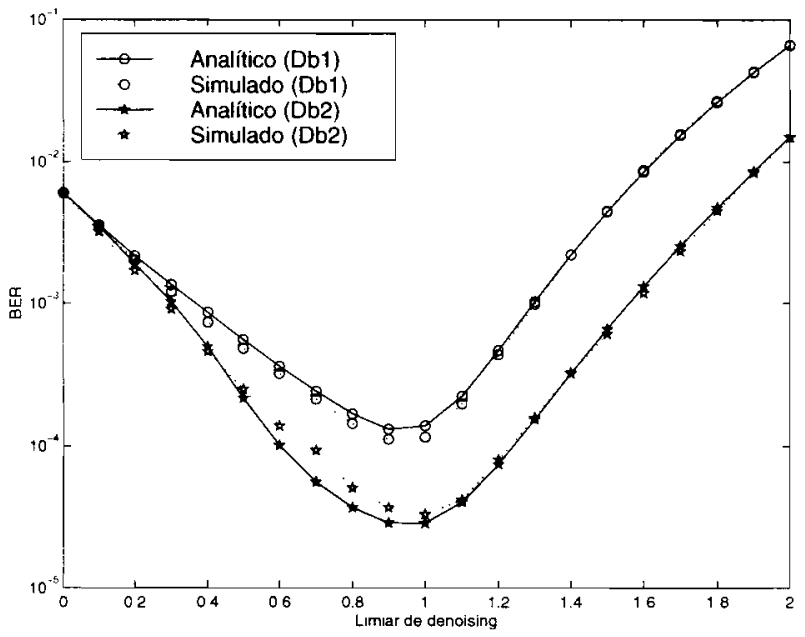

Figura 3. BER $\times$ limiar de denoising para as funções de base Db1 e Db2 considerando $J=3, P=32$ e RSR $=4 \mathrm{~dB}$.

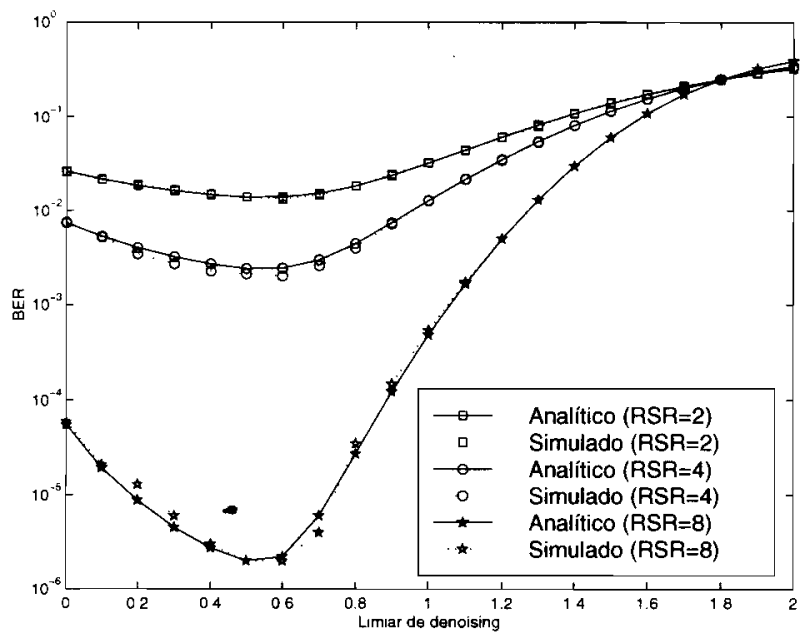

Figura 4. BER $\times$ limiar de denoising para RSR de 2,4 e 8 $\mathrm{dB}$ considerando Dbl, $J=2$ e $P=16$.

Apesar de se ter utilizado apenas seis momentos na aproximação analítica da fdp da VA $r$, a análise global dos resultados apresentados nas figuras supracitadas mostra um bom ajuste entre as curvas obtidas mediante aproximação analítica e aquelas geradas por simulação computacional.

Cabe notar que com o aumento do limiar, o termo referente

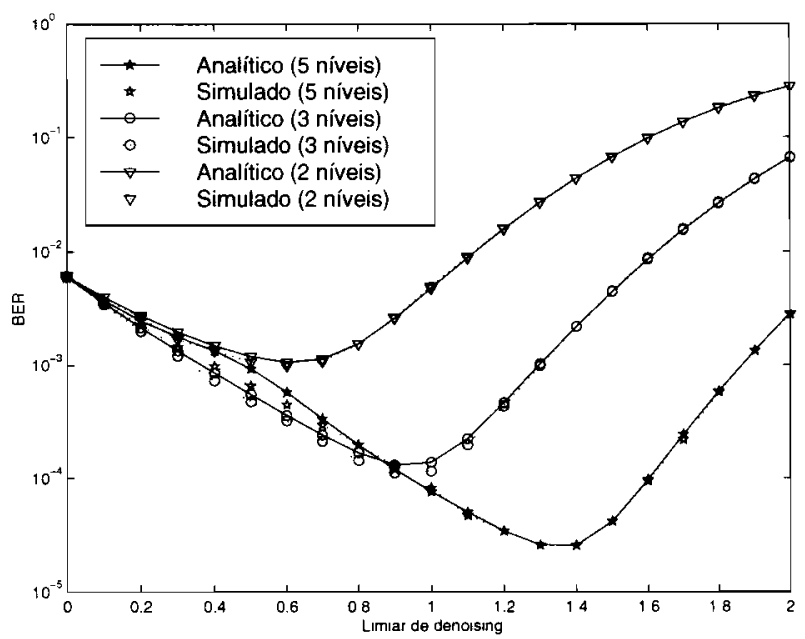

Figura 5. $\mathrm{BER} \times$ limiar de denoising para $J=2,3$ e 5 considerando Db1, $P=32$ e RSR $=4 \mathrm{~dB}$.

ao impulso da fdp na saída do procedimento de denoising vai se tornando mais importante. Por outro lado, para valores pequenos de limiar, o denoising exerce pouca influência. Diante disso, a aproximação realizada com as técnicas dos momentos é mais importante na faixa intermediária de valores do limiar de denoising. Em razão disso, observa-se nessas faixas de valores um pequeno desajuste entre os resultados analíticos e simulados apresentados nesta seção. Esse desajuste pode ser reduzido aumentando a quantidade de momentos usados na aproximação. No entanto, é importante notar que as curvas apresentadas são precisas para fins de determinação do limiar de denoising ótimo.

A Figura 3 ilustra a dependência do desempenho do pré-processamento baseado em denoising com respeito as funções de base empregadas, devido ao fato de que a propriedade de representação com parcimônia, depende da "adequação" entre as funções de base e os sinais a serem expandidos.

Vale notar que as Figuras 3, 4 e 5 indicam que o desempenho da técnica proposta é sensivelmente dependente do valor assumido pelo limiar de denoising. Com relação a este aspecto é importante fazer alguns comentários.

Para elevados valores do limiar, poucos coeficientes passam pelo procedimento de comparação, provocando, como discutido anteriormente, elevada polarização e pequena variância do estimador. Nessas condições, verificou-se por meio de simulações, cujos resultados não são apresentados, que os sinais na entrada do decisor são extremamente suaves (componentes de altas freqüências do sinal de interesse são suprimidas), corroborando a argumentação acima emitida.

Por outro lado, para $\lambda$ pequeno, muitos coeficientes passam incólumes pelo procedimento de denoising, prejudicando o processo de redução da potência do ruído, o que leva a uma situação inversa da anterior: estimação com grande variância e pequena polarização. Isso também foi constatado mediante simulação computacional.

Em suma, tanto para pequenos quanto para elevados valores de $\lambda$, os desempenhos observados foram severamente degradados em comparação ao produzido pelo uso do limiar ótimo. No primeiro caso isso se deve à pequena redução 
do nível de ruído (grande variância) e no segundo à grande polarização do estimador, resultante da supressão de uma parte considerável da energia do sinal transmitido.

Um aspecto a ser destacado a partir do conjunto de resultados numéricos apresentados é que o valor do limiar ótimo para realizar o procedimento de denoising suave, no contexto investigado, se altera significativamente com a quantidade de níveis de resolução, como pode ser observado na Figura 5. Para dois e cinco níveis de resolução os valores ótimos desse parâmetro são respectivamente 0,6 e 1,4. Mais importante ainda: o uso de $\lambda=0,6$ no segundo caso provoca uma severa degradação de desempenho. Por outro lado, o valor do limiar ótimo é pouco influenciado pelo tipo de funções de base e RSR.

Não foram apresentados resultados de simulação estimando o desempenho do esquema proposto sob a condição de variação do fator de superamostragem $(P)$, diante disso é importante esclarecer alguns aspectos.

$\mathrm{Na}$ análise apresentada na seção anterior é admitido que as amostras de ruído na saída do filtro limitador são descorrelacionadas. Assim sendo, para garantir essa condição na simulação, à medida que se aumenta $P$ deve também ser aumentada, na mesma proporção, a largura de banda deste filtro. Esse aumento na largura do filtro determina, por seu turno, um acréscimo na potência de ruído que contamina as observação, reduzindo a RSR. Por outro lado, o aumento de $P$, como explicado na introdução deste trabalho, facilita a remoção do ruído, proporcionando um melhor desempenho das técnicas de denoising.

Os efeitos que surgem com a variação de $P$ são claramente conflitantes. No entanto, o emprego de superamostragem combinada com a hipótese de ruído branco na entrada do procedimento de denoising torna o procedimento proposto sem importância prática. Isso foi imposto para facilitar a análise e não decorre de uma limitação da técnica proposta. Receptores práticos empregando a abordagem proposta e que apresentem um melhor compromisso de desempenho podem ser obtidos desvinculando o fator de superamostragem da largura de banda do filtro de recepção, permitindo o surgimento de ruído colorido na entrada do procedimento de denoising. $\mathrm{Na}$ próxima seção esse aspecto é explorado.

Apesar de pequeno, o conjunto de resultados apresentados nesta seção mostra que vários parâmetros influenciam de forma significativa o desempenho do esquema de recepção que emprega o processamento de entrada baseado em denoising. Este fato valoriza a análise matemática realizada, uma vez que ela possibjlita avaliar rapidamente o desempenho do referido esquema de recepção para diferentes combinações de formato de pulso básico de transmissão, transformada wavelet, limiar de denoising, níveis de resolução e fator de superamostragem.

\section{DESEMPENHO DO PRÉ-PROCES- SAMENTO BASEADO EM DENOIS- ING EM CANAIS SELETIVOS EM FREQÜÊNCIA}

Nesta seção são apresentados novos resultados de avaliação de desempenho obtidos via simulação, con- siderando a aplicação da estratégia de pré-processamento proposta em [1] a canais seletivos em freqüência. A estrutura de pré-processamento avaliada nesta seção apresenta algumas diferenças em relação à discutida anteriormente, especialmente no que se refere à técnica de denoising, como será visto na seqüência. Vale mencionar de antemão que, devido à necessidade do uso de superamostragem na implementação do processamento de entrada baseado em denoising, em geral, as amostras de ruído são correlacionadas.

As técnicas de denoising discutidas empregam estratégia de mapeamento suave com limiares de escopo local. Estratégias que empregam limiares de escopo local são especialmente atrativas quando o ruído que contamina o sinal é colorido. Nesses casos, a correlação existente entre as amostras do ruído causa uma concentração de sua energia no domínio da transformada.

De acordo com o esquema de escopo local adotado, para cada nível de resolução da transformada é empregado um limiar diferente $\lambda_{j}[2,9,10]$. Combinando a estratégia de mapeamento suave com este esquema de escopo local, os coeficientes no domínio da transformada após o procedimento de denoising, denotados por $\left\{\hat{\theta}_{j, k}\right\}$, são dados por

$$
\hat{\theta}_{j, k}=\operatorname{sgn}\left(\alpha_{j, k}\right)\left(\left|\alpha_{j, k}\right|-\lambda_{j}\right) \mathcal{I}_{\left(\left|\alpha_{j, k}\right|>\lambda_{j}\right)}, j \leq J,
$$

na qual $\alpha_{j, k}$ são os coeficientes da transformada wavelet da observação ruidosa, $j$ representa um nível de resolução particular da DWT, $\mathcal{I}_{(\mathcal{A})}$ representa a função indicadora do conjunto $\mathcal{A}$ e $J$ denota o nível de maior resolução da transformada.

Para obter os coeficientes referentes aos menores níveis de resolução da transformada, as amostras do sinal passam por sucessivos processos de filtragem passa-baixas. Como o sinal de interesse deve apresentar um conteúdo espectral nas baixas frequiências maior do que o ruído, sua concentração de energia nesses níveis de resolução é maior do que aquela obtida para o ruído. Essa mesma conclusão pode ser obtida lançando mão de argumentos oriundos da abordagem estatística: o sinal é por hipótese mais correlacionado do que o ruído, o que permite uma maior concentração de sua energia nos níveis de menor resolução.

A redução de amplitude dos coeficientes referentes aos menores níveis de resolução da transformada pode aumentar sobremaneira a polarização do estimador. Este é um risco desnecessário, pois, como discutido acima, pouca energia do ruído deve estar presente nesses coeficientes. Diante disso, se propõe que apenas os coeficientes referentes aos níveis de resolução de $J_{s}$ em diante, sendo a escolha deste parâmetro discutida na próxima seção, passem pelo processamento nãolinear. Os demais devem ficar inalterados. Algebricamente esse procedimento é dado por

$\hat{\theta}_{j, k}= \begin{cases}\alpha_{j, k} & j \leq J_{s} \\ \operatorname{sgn}\left(\alpha_{j, k}\right)\left(\left|\alpha_{j, k}\right|-\lambda_{j}\right) \mathcal{I}_{\left(\left|\alpha_{j, k}\right|>\lambda_{j}\right)} & j>J_{s}\end{cases}$

É importante mencionar que a escolha de $J_{s}$ permite estabelecer um compromisso entre a variância e a polarização do estimador. Elevados valores de $J_{s}$ tendem a aumentar a variância e reduzir a polarização do estimador, enquanto que pequenos valores de $J_{s}$ tendem a aumentar a sua polarização e reduzir a sua variância. 
Para implementar o procedimento proposto na Equação 51 é preciso determinar os valores dos limiares. Existem vários métodos para estabelecê-los $[10,11]$, dentre os quais, foi escolhido o seguinte

$$
\lambda_{j}=\hat{\sigma}_{j} \sqrt{2 \log \left(n_{j}\right)} \text { para } j=J_{s}+1, \cdots, J
$$

sendo $\hat{\sigma}_{j}$ um fator de escala referente ao $j$-ésimo nível de resolução e $n_{j}$ a quantidade de coeficientes desse nível.

$O$ fator $\hat{\sigma}_{j}$ pode ser obtido a partir dos coeficientes da transformada wavelet da observação ruidosa do $j$-ésimo nível de resolução, da seguinte forma

$$
\hat{\sigma}_{j}^{2}=\frac{\operatorname{MAD}\left(\alpha_{j . k}\right)}{0,6745}
$$

sendo $\operatorname{MAD}\left(\alpha_{j . k}\right)$ o desvio absoluto médio dos coeficientes do $j$-ésimo nível de resolução e 0,6745 uma constante de calibração, específica para a distribuição gaussiana [10].

\subsection{O SISTEMA SIMULADO}

O diagrama de blocos simplificado do sistema de comunicações simulado é apresentado na Figura 6 . A fonte gera símbolos estatisticamente independentes e identicamente distribuídos. O transmissor é composto de modulador QPSK e filtro de transmissão.

A RI do canal é modelada por um filtro transversal com coeficientes invariantes no tempo e igualmente espaçados a intervalos de $\frac{T}{2}$.

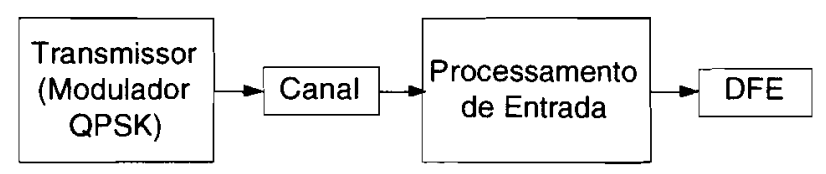

Figura 6. Diagrama de blocos do sistema simulado.

O ruído assume valores complexos e é modelado por um processo aleatório estacionário em sentido amplo, cujas componentes real e imaginária são estatisticamente independentes. A especificação de primeira ordem dessas componentes é dada por VA gaussianas de média nula e variância $\sigma^{2}$.

O esquema de recepção é composto basicamente de dois blocos: o processamento de entrada e o equalizador. Com relação ao processamento de entrada duas estruturas são avaliadas. A primểira, nesta seção rotulada de convencional, é composta basicamente de filtro linear invariante ao deslocamento e amostrador. O segundo, doravante denominado de processamento de entrada proposto, se baseia no emprego de técnicas de denoising. Por fim, o uso de equalizador se faz necessário em função do tipo de canal de comunicação considerado. O equalizador utilizado é do tipo DFE.

As estratégias do processamento de entrada consideradas nesta seção estão mostradas na Figura 7. Em particular, a estratégia convencional é ilustrada na Figura 7a. Como pode ser verificado, este esquema emprega um amostrador que opera na taxa de símbolos, enquanto que o procedimento proposto emprega uma amostragem com taxa $P$ vezes maior.
No esquema convencional, empregou-se filtros de transmissão e de recepção casados com resposta ao impulso dada pela raiz quadrada do cosseno levantado com fator de excesso de faixa igual a $15 \%$ [12]. ${ }^{5}$ No esquema proposto, por seu turno, foi adotado na transmissão um filtro do tipo cosseno levantado com fator de excesso de faixa igual a $15 \% \mathrm{e}$, na recepção, um filtro de Butterworth de segunda ordem, cuja largura de banda de $3 \mathrm{~dB}$ é aqui denotada por $B_{c}[13,14]$.

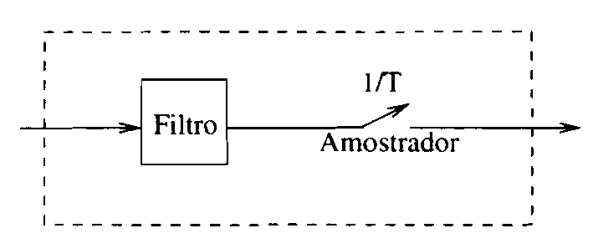

(a) Processamento de entrada convencional

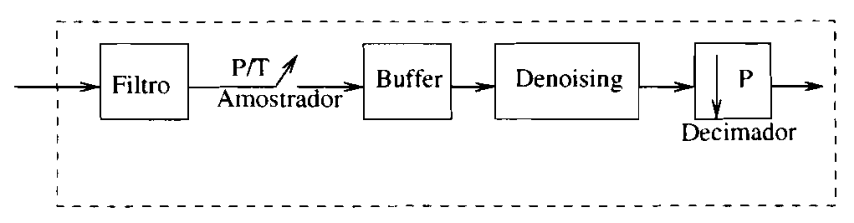

(b) Processamento de entrada proposto

Figura 7. Diagrama de blocos do processamento de entrada convencional e proposto.

O procedimento de entrada opera em um conjunto de $N$ intervalos de símbolo, ao contrário do esquema apresentado na seção anterior, que considerava apenas amostras tomadas dentro de um intervalo de símbolo.

É importante verificar que o procedimento de entrada baseado em denoising demanda mais recursos computacionais do que o procedimento convencional, devido ao uso da técnica de denoising, cuja complexidade decorre essencialmente do uso da DWT, e de superamostragem.

Considerando que a observação é formada por $P N$ amostras (sendo $N$ o número de símbolos por bloco), a complexidade da DWT, expressa em termos do número de operações de ponto flutuante é dada por $\mathrm{O}(P N)$ [11]. Além disso, o esquema proposto introduz um retardo na decisão de $N$ símbolos. Por outro lado, as especificações do filtro de recepção podem ser relaxadas, uma vez que o combate ao ruído é realizado principalmente pelo procedimento de denoising. Outro aspecto interessante é que, como não existe a necessidade de se adotar filtros casados no processamento de entrada, o filtro de transmissão pode ser projetado para favorecer ou atender outros requisitos de projeto.

\subsection{RESULTADOS NUMÉRICOS}

A taxa de erro de bit (BER) é novamente o parâmetro de desempenho usado para avaliar o funcionamento dos esquemas de recepção sob investigação. Os valores de BER são

\footnotetext{
SAlguns resultados de simulação, que não são aqui apresentados, foram obtidos considerando outros valores de fator de excesso de faixa e revelaram em sua essência comportamentos similares aos obtidos para o valor de excesso de faixa mencionado acima.
} 
computados em função da razão entre a energia do bit $\left(E_{b}\right) \mathrm{e}$ a densidade espectral de potência do ruído $\left(N_{0}\right)$.

O objetivo principal desta seção é investigar o comportamento do esquema de recepção variando alguns parâmetros importantes do processamento de entrada proposto.

As curvas de BER apresentadas nesta seção foram obtidas considerando a transmissão de $10^{5}$ blocos independentes, cada qual composto de 512 símbolos. O treinamento do DFE foi realizado antes da recuperação da informação transmitida, usando o algoritmo de filtragem adaptativa LMS e uma seqüência pseudo-aleatória composta de 64 símbolos. $\mathrm{O}$ fator de superamostragem foi fixado em dezesseis $(P=16)$. Além disso, todos os resultados de simulação apresentados nesta seção foram obtidos considerando que a DWT possui sete níveis de resolução $(J=7)$.

Três canais, referidos como $\mathrm{Ch} 1, \mathrm{Ch} 2$ e $\mathrm{Ch} 3$, cujas RI têm coeficientes dados pelos vetores $(0,9014,0,4294$, $-0,0531, \quad-0.0178, \quad 0,0058), \quad(0,7767,-0,5097,-0,1514$, $0,3223,0,1007)$ e $(0,7061,-0,5776,-0,0949,0,3821$, 0,1130 ), respectivamente, são considerados nas simulações. Esses canais possuem atrasos espaçados na metade do intervalo de símbolo $(T / 2)$ e suas respostas em amplitude são mostradas na Figura 8, na qual o eixo de freqüências é normalizado pela taxa de transmissão.

Como fica evidente a partir da figura supracitada, o canal $\mathrm{Ch} \mathrm{l}$ apresenta resposta em amplitude pouco dispersiva, oferecendo um pequeno grau de dificuldade para o equalizador, ao contrário dos outros dois canais que contém picos de atenuação dentro da banda de interesse. Em particular, a resposta em amplitude do canal Ch3 mostra um pico de atenuação extremamente pronunciado na faixa de interesse.

É importante verificar ainda que as respostas ao impulso desses canais não apresentam precursores, ou seja, o primeiro raio é o dominante. Como conseqüência deste fato, o DFE projetado apresenta uma estrutura simplificada, na qual apenas a seção de realimentação é incorporada. Neste caso, a matriz de correlação do sinal de referência é dada por uma matriz identidade, situação em que o algoritmo adaptativo LMS produz suas melhores características de desempenho $[15,16]$. Diante disso, optou-se por usá-lo para estimar os parâmetros do equalizador durante a fase de treinamento.

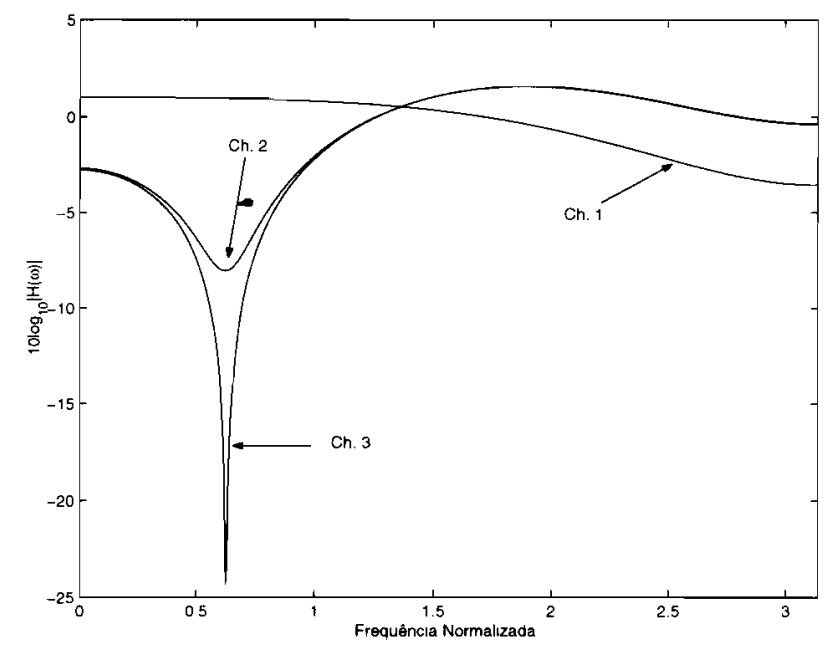

Figura 8. Resposta em amplitude dos canais simulados.
$\mathrm{Na}$ Figura 9 é apresentado o desempenho do receptor que emprega o processamento de entrada proposto em função da largura de banda do filtro de recepção $\left(B_{c}\right)$. Os resultados são obtidos para o canal $\mathrm{Ch} 3$, utilizando as funções de base da família Daubechies com cinco graus de regularidade [8], denotada por Db5, e $J_{s}=4$.

Nesta figura são incluídos resultados para 14 e $18 \mathrm{~dB}$ de razão sinal-ruído $\left(E_{b} / N_{0}\right)$. Além disso, são incluídos também os resultados obtidos para o esquema de recep̧ão com o processamento de entrada convencional. Neste caso, como $B_{c}$ é um parâmetro que afeta apenas o processamento de entrada proposto, as curvas de desempenho mostradas são paralelas ao eixo horizontal.

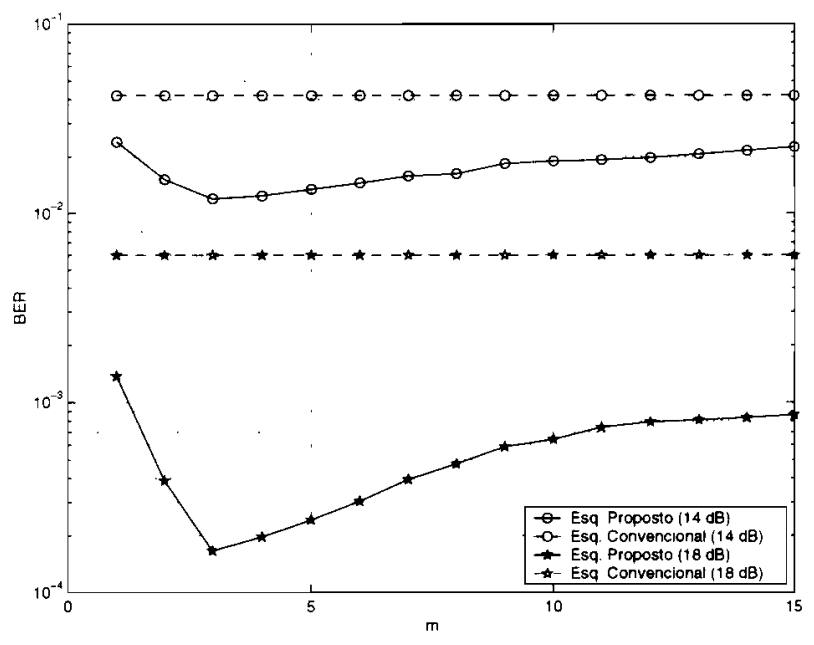

Figura 9. Desempenho em função da largura de banda do filtro de recepção $(m / T \mathrm{~Hz})$ para $E_{b} / N_{0}=14$ e $18 \mathrm{~dB}$.

Os resultados apresentados na Figura 9 mostram claramente que o esquema de recepção que emprega o processamento de entrada proposto supera o desempenho do esquema de recepção que usa o processamento de entrada convencional, para todos os valores de $B_{c}$ considerados.

$O$ alargamento da banda de passagem do filtro de recepção aumenta a potência do ruído na entrada do procedimento de denoising e reduz a correlação entre as amostras do ruído. Essas tendências provocam efeitos conflitantes no procedimento de denoising. Enquanto o primeiro prejudica o seu desempenho, o segundo favorece-o, na medida que haverá maior concentração da energia do sinal transmitido no domínio da transformada ao passo que a energia do ruído, na média, se distribui igualmente pelos coeficientes da transformada wavelets. Conforme indicado na Figura 9, o procedimento proposto produziu um desempenho melhor para $B_{c}=3 / T$. Além desse valor, o impacto negativo provocado pelo aumento da potência do ruído na entrada do procedimento de denoising parece ser mais significativo do que os benefícios oriundos da redução de correlação de suas amostras.

Nas Figuras 10 e 11 são apresentadas curvas de desempenho para o receptor que emprega o processamento de entrada proposto. Esses resultados foram obtidos variando alguns parâmetros importantes da técnica de denoising. Os resultados mostrados na Figura 10 foram obtidos com $J_{s}=4 \mathrm{e}$ funções de base do tipo Daubechies com cinco, sete e nove 
graus de regularidade, neste artigo denotadas por Db5, Db7 e $\mathrm{Db} 9$, respectivamente. Já os resultados apresentados na Figura 11 foram obtidos usando as funções de base Db5 e quatro diferentes valores de $J_{s}$. Em ambos os casos foi considerado o canal $\mathrm{Ch} 3$ e $E_{b} / N_{0}$ variando de 0 a $30 \mathrm{~dB}$ com incrementos de $2 \mathrm{~dB}$. Além disso, empregou-se $J=7$ e $B_{\mathrm{c}}=3 / T$.

Os resultados apresentados nas Figuras 10 e 11 ilustram a sensibilidade do desempenho do esquema de recepção à escolha das funções de base e à quantidade de níveis de resolução cujos coeficientes passam incólumes pelo procedimento de denoising $\left(J_{s}\right)$. A seguir esses resultados são discutidos em maiores detalhes.

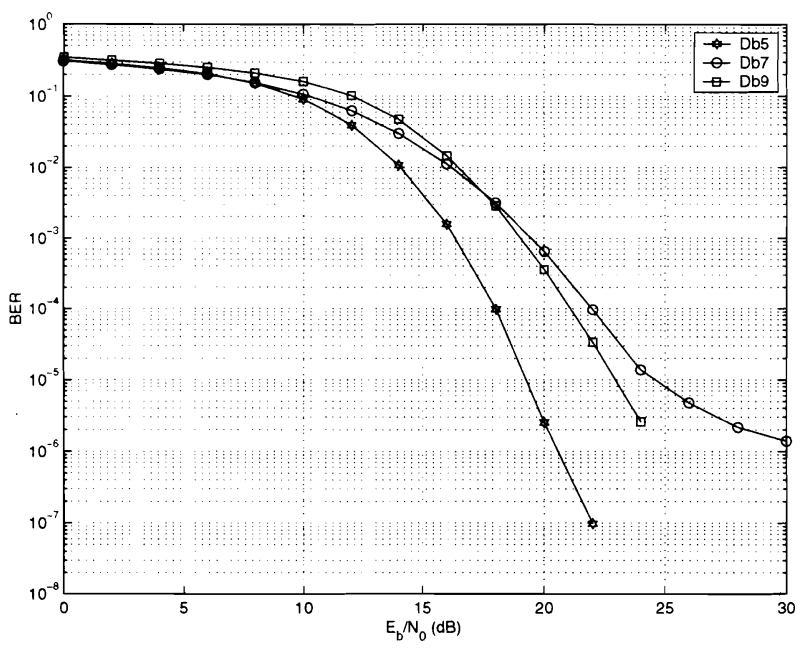

Figura 10. Desempenho do esquema proposto para algumas funções de base.

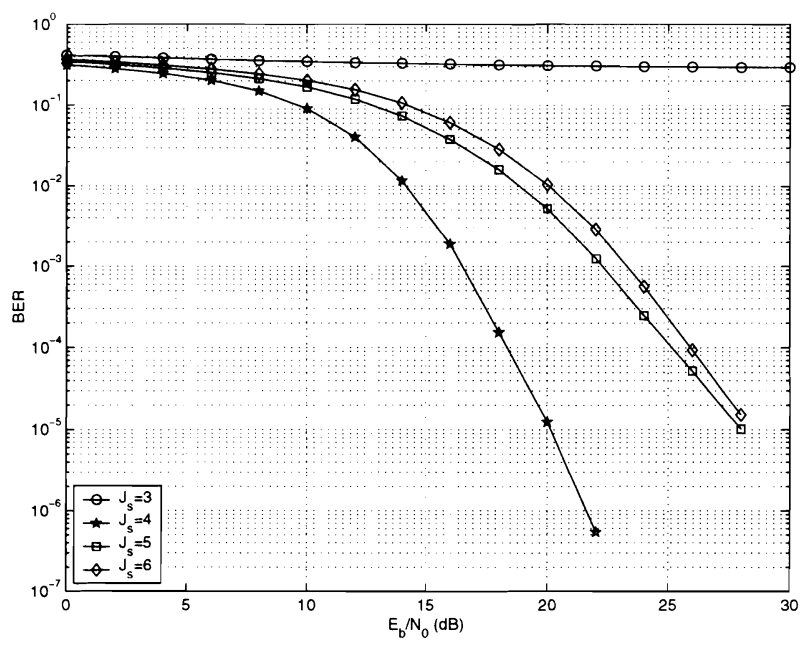

Figura 11. Desempenho do esquema proposto para alguns valores de $J_{s}$.

Como mostrado na Figura 10, os melhores resultados foram obtidos para as funções de base Db5, principalmente para altos valores de $E_{b} / N_{0}$, ao passo que os piores foram verificados para as funções de base $\mathrm{Db} 7$. Neste último caso observou-se inclusive uma tendência ao surgimento de piso na curva de probabilidade de erro.

No que se refere aos resultados apresentados na Figura 11, pode-se observar claramente que a escolha de $J_{s}$ exerce um forte impacto na taxa de erro de bit do esquema proposto. Para um pequeno valor de $J_{s}$, coeficientes com conteúdo significativo de energia do sinal de interesse podem ser excluídos, produzindo uma estimativa do sinal transmitido muito suavizada (estimador com polarização grande). Por outro lado, se o valor de $J_{s}$ é muito elevado, a redução na potência do ruído fica comprometida, produzindo uma estimativa com grande variância. De acordo com os resultados apresentados na Figura 11, um bom compromisso entre polarização e variância pode ser obtido com $J_{s}=4$.

É importante mencionar que em outras simulações realizadas, cujos resultados não são apresentados, revelam que o valor ótimo de $J_{s}$ está visceralmente relacionado com a quantidade de níveis de resolução da transformada $(J)$, observando-se um aumento do primeiro quando o segundo aumenta.

Considerando um sinal com uma quantidade fixa de amostras, deve-se notar que o número de coeficientes por nível depende da quantidade total de níveis de resolução da transformada $(J)$. Foi verificado, por simulação computacional, que a capacidade de concentração de energia da transformada não é muito influenciada por $J$. Além disso, cabe lembrar que cerca de $50 \%$ dos coeficientes da transformada pertencem ao nível $J, 25 \%$ deles pertencem ao nível $J-1$, $12,5 \%$ pertencem ao nível $J-3$ e assim em diante. Dessa forma, admitindo que a maior parte da energia do sinal de interesse fica confinada em um certo percentual dos coeficientes, a quantidade de níveis a que estes coeficientes pertence é diretamente proporcional a $J$.

Os resultados da comparação de desempenho entre os esquemas de recepção que empregam o processamento de entrada proposto e o convencional são mostrados na Figura 12 considerando os canais $\mathrm{Ch} 1, \mathrm{Ch} 2$ e $\mathrm{Ch} 3$. O esquema proposto foi simulado com funções de base $\mathrm{Db} 5, J_{s}=4$ e $B_{c}=3 / T$. Nessa figura inclui-se também a curva de probabilidade de erro de bit teórica para um esquema de modulação QPSK em canal AWGN.

A Figura 12 mostra claramente que o desempenho do receptor que emprega o processamento de entrada proposto é sempre melhor do que o do esquema de recepção com processamento de entrada convencional. Verifica-se também que a vantagem de desempenho propiciada pelo primeiro depende da RI do canal. Por exemplo, para uma taxa de erro de $10^{-5}$ os ganhos observados são de $0,5 \mathrm{~dB}$ para o canal Ch1, $4 \mathrm{~dB}$ para o canal $\mathrm{Ch} 2$ e superior a $5 \mathrm{~dB}$ para o canal $\mathrm{Ch} 3$, indicando que essa vantagem aumenta à medida que o pico de atenuação dentro da faixa espectral de interesse fica mais pronunciado. Em particular, obteve-se um considerável ganho em termos de $E_{b} / N_{0}$ para o canal Ch3. Outros resultados obtidos anteriormente para canais com diferentes RIs, também indicaram a validade desta conjectura [1]. Além disso, nessa referência é realizada uma comparação de desempenho do esquema proposto em relação ao propiciado por esquemas de equalização convencionais que operam na taxa de amostragem e fracionários $\left(\frac{T}{2}\right)$. Todos os resultados lá apresentados são favoráveis ao esquema proposto. 


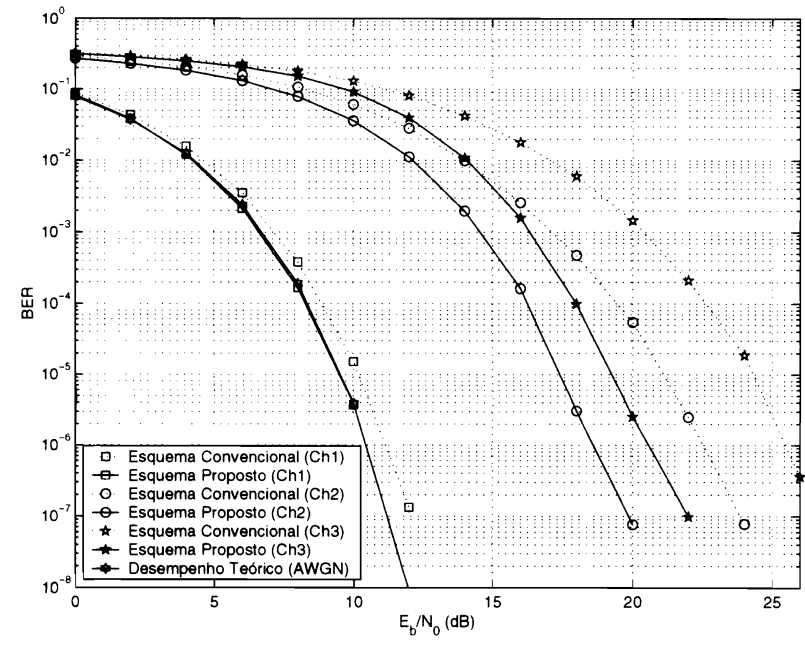

Figura 12. Desempenho dos esquemas convencional e proposto para os canais $\mathrm{Ch} 1, \mathrm{Ch} 2$ e Ch3. Inclui-se também a curva de probabilidade de erro de bit para o canal AWGN.

\section{CONCLUSÃO}

Por meio de análise matemática e simulações por computador foi avaliado neste trabalho um novo processamento de entrada para receptores digitais, cuja capacidade de remoção de ruído advém do uso de técnicas de denoising.

Inicialmente, considerando canais AWGN, o uso de mapeamento suave e limiar de escopo global, a probabilidade de erro do esquema supracitado foi obtida analiticamente, usando técnicas de momentos para aproximar a fdp do sinal na entrada do decisor. É importante ressaltar que, apesar do modelo de sistema de comunicação ser simples, o processamento de entrada baseado em denoising é não-linear, e obter expressões para probabilidade de erro nessas condições é, em geral, uma tarefa árdua. Nesse caso não foi diferente. Muitas dificuldades foram encontradas, especificamente no que se refere ao uso das técnicas dos momentos. Essas dificuldades foram sendo suplantadas mediante soluções originais propostas.

Uma importante dificuldade veio à tona pelo fato da fdp de interesse possuir descontinuidade e um impulso na origem, características que conjuntamente impõem sérias restrições de desempenho às técnicas dos momentos. Nesse caso, foram realizadas manipulações algébricas para contornar ou solucionar esses inconvenientes separando a fdp em três partes: uma referente ao impulso, outra decorrente da descontinuidade e a última uma função contínua.

Como fruto da análise realizada, obteve-se uma aproximação analítica da fdp do sinal na entrada do decisor dividida em três parcelas, cada qual decorrente das partes supracitadas. Para as duas primeiras parcelas, que impunham sérias restrições de desempenho às técnicas dos momentos, foram fornecidas expressões fechadas a partir da expansão wavelet do pulso básico de transmissão. A última parcela, por seu turno, foi obtida por aproximação analítica a partir de seus momentos estatísticos, os quais foram determinados analiticamente.

A partir da fdp do sinal na entrada do decisor chegou-se à expressão para a probabilidade de erro de bit do esquema de recepção, a qual ficou especificada em termos de parâmetros do procedimento de denoising. Além disso, foram obtidas curvas de desempenho via simulação de Monte Carlo em função do limiar de denoising para alguns valores de RSR, funções de base wavelets e níveis de resolução. Esses resultados corroboraram as deduções que foram obtidas, usando a técnica de Gram-Charlier com seis momentos.

Posteriormente foram apresentados novos resultados de desempenho, obtidos mediante simulação computacional considerando a aplicação do pré-processamento baseado em denoising para sistemas mais complexos, principalmente no que tange ao uso de modelos de canais seletivos em freqüência. Alguns dos canais investigados se caracterizam por apresentar severa atenuação dentro da banda espectral de interesse.

Os resultados apresentados indicam que o desempenho produzido pelo processamento de entrada baseado em denoising é sensivelmente afetado por alguns parâmetros importantes, tais como o tipo de funções de base wavelets e a quantidade de níveis de resolução cujos coeficientes não são afetados pelo procedimento de denoising. Para uma configuração adequada desses parâmetros, verificou-se que o desempenho do processamento de entrada baseado em denoising supera o de esquemas convencionais, principalmente quando o canal de comunicação apresenta nulos espectrais dentro da banda de freqüências de interesse. Esse comportamento também foi observado com outros casos investigados em [1] e pode ser uma grande vantagem para aplicações na área de comunicações móveis, visto que nesses casos os canais usualmente apresentam nulos espectrais na faixa de transmissão.

É importante mencionar que a investigação da escolha de parâmetros do processamento de entrada baseado em denoising foi bastante limitada em escopo. Alguns parâmetros não foram contemplados, e quando o foram, apenas algumas possibilidades de escolha desses parâmetros foram consideradas.

Diante do exposto acima, os resultados da comparação deste trabalho são bastante animadores e motivam a continuação de pesquisas nessa área a fim de que as potencialidades da técnica proposta em [1] sejam exploradas plenamente. Dentre as linhas de pesquisa que se pretende seguir destacam-se a investigação da possibilidade em estender os resultados analíticos para contemplar os casos que envolvem canais seletivos em freqüência e variante no tempo e avaliar o desempenho de esquemas que empregam técnicas de denoising mais elaboradas, como por exemplo as que levam em conta a correlação dos coeficientes de um mesmo nível da transformada wavelet [17] e as que adotam esquemas de remoção de ruído de forma iterativa [18].

\section{AGRADECIMENTOS}

Os autores gostariam de expressar seus agradecimentos ao Conselho Nacional de Desenvolvimento Científico e Tecnológico $(\mathrm{CNPq})$ pelo apoio financeiro, e aos revisores anônimos pelas valiosas críticas e sugestões, que muito contribuíram para melhorar a qualidade deste artigo. 


\section{REFERÊNCIAS}

[1] J. F. Galdino, E. L. Pinto and M. S. Alencar. "Using Denoising at the Receiver Front-end for Frequency-Selective Channels". IEEE Transactions on Communications, vol. 51, no. 5, pp. 727-729, May 2003.

[2] D. L. Donoho. "De-Noising by Soft-Thresholding". IEEE Transactions on Information Theory, vol. 41, no. 3, pp. 613627, May 1995.

[3] I. M. Johnstone and D. L. Donoho. "Ideal Spatial Adaptation via Wavelet Shrinkage”. Biometrika, vol. 81, pp. 425-455, 1994.

[4] B. Vidakovic. Statistical Modeling by Wavelets. John Wiley, 1999.

[5] J. F. Galdino. "Alternativas de Redução de Ruído e Exploração de Algoritmos de Filtragem Adaptativa em Receptores para Canais Seletivos em Freqüência". Tese de doutorado, Universiade Federal de Campina Grande (UFCG), Dezembro 2002.

[6] G. H. Golub and C. F. Van Loan. Matrix Computations. Johns Hopkins, 1996.

[7] A. Papoulis. Probability, Random Variables, and Stochastic Processes. McGraw-Hill, 1991.

[8] I. Daubechies. Ten Lectures on Wavelets. SIAM, 1992.

[9] S. Mallat, H. Krim, D. Tucker and D. Donoho. "On Denoising and Best Signal Representation". IEEE Transactions on Information Theory, vol. 45, no. 7, pp. 2225-2238, November 1999.

[10] I. M. Johnstone and B. W. Silverman. "Wavelet Threshold Estimators for Data with Correlated Noise". J. Roy. Statist. Soc., vol. Ser. B, no. 59(2), pp. 319-351, 1997.

[11] R. T. Ogden. Essential Wavelets for Statistical Applications and Data Analysis. Birkhäuser, 1997.

[12] J. G. Proakis. Digital Communications. McGraw-Hill, 1995.

[13] S. U. H. Qureshi. "Adaptive Equalization". Proceedings of the IEEE, vol. 73, no. 9, pp. 1349-1387, September 1985.

[14] J. Treichler, I. Fijalkov and C. Johnson. "Fractionally Spaced Equalizers". IEEE Signal Processing Magazine, pp. 65-81, May 1996.

[15] P. S. R. Diniz. Adaptive Filtering Algorithms and Practical Implementation. Kluwer Academic Publishers, 1997.

[16] S. Haykin. Adaptive Filter Theory. Prentice Hall, 1991.

[17] G. Y. Chen and T. D. Bui. "Multiwavelets Denoising Using Neighboring Coefficients". IEEE Signal Processing Letters, vol. 10, no. 7, pp. 211-214, July 2003.

[18] R. Ranta, C. Heinrich, V. Louis-Dorr and D. Wolf. "Interpretation and Improvement of the Iterative Wavelet-Based Denoising Method". IEEE Signal Processing Letters, vol. 10, no. 8, pp. 239-241, August 2003.

Juraci Ferreira Galdino nasceu em Malta, Paraíba, em 1967. Formou-se em Engenharia Elétrica pela Universidade Federal da Paraíba em 1991. Formou-se Oficial Engenheiro Militar do Exército Brasileiro pelo Instituto Militar de Engenharia em 1992. Recebeu o título de mestre em Engenharia Elétrica pelo Instituto Militar de Engenharia em 1998 e o título de Doutor em Ciências pela Universidade Federal de Campina Grande em Dezembro de 2002. Desde Janeiro de 2003 é professor do Instituto Militar de Engenharia. Suas pesquisas concentram-se principalmente em wavelets, filtragem adaptativa e comunicações móveis. É autor de diversos trabalhos publicados em anais de congressos de sociedades científicas nacionais e internacionais e um dos autores do livro Communications, Information and Network Security, pela Kluwer Academic Publishers. Juraci Ferreira Galdino é membro da Sociedade Brasileira de Telecomunicações (SBrT).
Ernesto Leite Pinto graduado em Engenharia Elétrica pela Universidade Federal da Paraíba, em 1983, tem mestrado e doutorado na área de sistemas de comunicações pela PUC/Rio, concluídos em 1986 e 1998, respectivamente. Suas principais áreas de pesquisa são: avaliação de desempenho de sistemas de transmissão digital e processamento digital de sinais aplicado a sistemas de comunicações digitais. É professor adjunto IV do Departamento de Engenharia Elétrica (DEE) do IME, onde trabalha desde 1987 e orientou diversas dissertações de mestrado. Exerce também a função de chefe da área de concentração de Telecomunicações do programa de mestrado do DEE/IME. Trabalhou recentemente como professor visitante e tem participado do programa de pós-graduação do Departamento de Engenharia Elétrica da Universidade Federal de Campina Grande, co-orientando teses de doutorado. É autor de diversos trabalhos publicados em anais de congressos e revistas de sociedades científicas nacionais e internacionais. Participou de várias bancas de avaliação de dissertações de mestrado e teses de doutorado em diversas instituições importantes do país. Trabalhou junto aos departamentos de treinamento da Eembratel e da Telerj, como autor de textos didáticos e professor, na área Comunicações Digitais. É sócio e fez parte do Conselho Deliberativo da Sociedade Brasileira de Telecomunicações.

Marcelo Sampaio de Alencar nasceu em Serrita, Pernambuco, em 1957. Formou-se em Engenharia Elétrica pela Universidade Federal de Pernambuco, em 1980, recebeu o título de mestre em Engenharia Elétrica pela Universidade Federal da Paraíba (UFPB), em 1988 e o de Ph.D. em Engenharia Elétrica pela University of Waterloo, Canada, em 1993. Durante o período de 1982 a 1984 trabalhou na Faculdade de Engenharia da Universidade para o Desenvolvimento do Estado de Santa Catarina, onde foi Membro Titular do Conselho Universitário e Vice-Presidente da Associação dos Professores. Atualmente trabalha no Departamento de Engenharia Elétrica da Universidade Federal de Campina Grande (UFCG), onde exerce o cargo de Professor Titular. Exerceu os cargos de ViceCoordenador do Curso de Engenharia Elétrica, Assessor de Extensão do Centro de Ciências e Tecnologia, Presidente da Comissão de Extensão do Centro de Ciências e Tecnologia da UFPB e foi Membro nato do Comitê Assessor de Extensão da Universidade Federal da Paraíba. Atualmente exerce a Coordenação do Grupo de Comunicações do Departamento, com cadastro no CNPq. Professor do Programa de Pós-graduação da Universidade Federal de Pernambuco (UFPE) e foi Professor do Programa de Pós-graduação Lato Sensu da Universidade Federal do Maranhão (UFMA). Foi Professor Visitante no Departamento de Engenharia Elétrica e de Computação, Universidade de Toronto, em 1997. Senior Member do IEEE. Revisor da revista IEEE Transactions on Communications, da Revista Brasileira de Telecomunicações, da Sociedade Brasileira de Telecomunicações, da revista IEEE Transactions on Vehicular Technology, da revista Wireless Personal Communications, da Kluwer Academic Publishers. Membro da Comissão Brasileira de Comunicações 2 da Anatel. Áreas de interesse em pesquisa: Processamento de Sinais, Comunicações Ópticas, Comunicações Móveis, Teoria da Comunicação e Informação, Efeitos Biológicos da Radiação, áreas em que tem mais de 100 artigos publicados. Tem sua biografia incluída nas publicações Who's Who in the World, Who's Who in Science and Engineering. Marcelo Sampaio de Alencar é autor dos livros Telefonia Digital (Quarta Edição) e Sistemas de Comunicações, pela Editora Érica Ltda, autor do livro Princípios de Comunicações, pela Editora Universitária, UFPB, um dos autores do livro Communications, Information and Network Security, pela Kluwer Academic Publishers, e articulista do Jornal do Commércio On Line, de Recife, assinando a coluna Difusão, de divulgação científica, desde abril de 2000 . 